\title{
A factorial structure of university absenteeism in higher
}

\section{education: A student perspective}

\author{
X. Triado-Iverna, P. Aparicio-Chueca ${ }^{* a}$, A. Elasri-Ejjaberia ${ }^{\mathrm{a}}$, I. Maestro- \\ Yarza $^{\mathrm{b}}$, M. Bernardo, P. Presas ${ }^{\mathrm{a}}$ \\ ${ }^{a}$ Department of Business, University of Barcelona, Spain; ${ }^{b}$ Department of Economic \\ History, Institutions and Policy and World Economy, University of Barcelona
}

Postal Address

Av. Diagonal, 690 (08034, Barcelona, Spain)

The aim of this study is to identify and analyse the most important reasons that influence absenteeism in university classrooms from the students' perspective. Data has been gathered through a questionnaire answered by 1,896 students from the Business Administration, Economics and Sociology degrees of the Universitat de Barcelona, Spain. Both a difference of means and exploratory factor analyses have been applied. Findings show that students differ on these reasons regarding their year and degree of study. The results of the factor analysis reveal five dimensions of reasons for absenteeism: (1) students' own planning, (2) teaching methodology, (3) learning methodology, (4) course characteristics, and (5) external sources available. These factors call for effective action lines that eliminate the inefficiencies of public resources. Keywords: student absenteeism; university; undergraduates; reasons for absenteeism; engagement

${ }^{*}$ Corresponding author. Email: pilaraparicio@ub.edu 


\section{Introduction}

Lately, there has been sharply increasing interest in absenteeism in university classrooms as it is essential in order to engage students (Triadó-Ivern, Aparicio-Chueca, Guàrdia, Peró-Cebollero \& Jaría-Chacón, 2013; López-Bonilla \& López-Bonilla, 2015). An absent student is considered to be the one not attending lessons despite being enrolled in them (Triadó-Ivern et al., 2013).

It is even more interesting if we consider that a higher education plan was implemented in Europe, the European Higher Education Area (EHEA) model, which aims, among other aspects, to make students more involved in class and have them play a central role, thus developing competences and increasing their capacity to work autonomously, on the basis of continuous assessment and not only of a single exam at the end of the semester (EU, 1999; Lozano, Romano \& Segovia, 2014).

Therefore, absenteeism is a phenomenon that contradicts the basic premises of the EHEA regarding the students' role. Moreover, the presence of students in the classroom is valuable to understand the context of knowledge and a requirement for the process of training skills. Additionally, this phenomenon causes other negative derivatives. For instance, it involves a waste of economic resources, scarce in itself in the public university system (OECD, 2018; Ramchander, 2017), which could be used to support interested students.

The reasons reported in the literature are inconclusive. In fact, there is little evidence available on this phenomenon and, although it is common according to the attention received, the literature aiming to minimise it is scarce (see e.g., Paisey \& Paisey, 2004; de Jorge Moreno, Gil, de Lucas \& Triguero, 2011). However, it is rather unusual to pay attention and develop controlled studies to analyse the reasons and possible causes of the absenteeism of university students, maybe because of the 
difficulty to evaluate this phenomenon as neither surveys nor other qualitative techniques are thorough enough, which makes this phenomenon even more interesting to investigate.

Romer (1993) presented the pioneering study on the topic and he revealed the absence of a third of the students. Pithers \& Holland (2007) summarised the results concerning attendance rates in a group of countries and Barlow and Fleischer (2011) wondered who was responsible for it. However, studies analysing the phenomenon of absenteeism while considering the students' profiles are scarce, as López-Bonilla and López-Bonilla (2015) suggested.

The current study aims to analyse the reasons for this phenomenon from the students' point of view. More specifically, the study seeks, firstly, to identify the students' perception regarding the reasons for absenteeism, and secondly, to analyse whether there are differences depending on their year of study and bachelor degree through a sample of students from the School of Economics and Business (SEB) of the Universitat de Barcelona (UB), Spain.

A previous research analysing absenteeism reasons was conducted by TriadóIvern et al. (2013), who collected data during the academic year 2007-2008, when university studies were in the process of implementing the new university model. Almost ten years after the EHEA, it is necessary to determine if the reasons persist. Therefore, the research question we pose is whether the reasons for absenteeism have changed after the implementation and consolidation of the EHEA model.

\section{Theoretical framework}

The non-attendance of the students may be due to diverse reasons. If students do not attend because they prefer to stay at home or spend time in leisure activities instead of 
going to class, it will be considered as voluntary. Involuntary absenteeism is the one caused by, e.g., a job or by overlapping courses (Driver \& Watson, 1989).

Non-attendance has negative consequences for students, teachers and universities. On the one hand, the literature shows a positive relationship between attendance and student performance (see e.g., Walker, Fleischer \& Winn, 2008; Landin \& Pérez, 2015). However, other authors have doubts about that association (Moore, Armstrong \& Pearson, 2008; Stoner \& Fincham, 2012). On the other hand, it has negative implications on the motivation of lecturers (Stoner \& Fincham, 2012), as well as on the relationship between students and lecturers and their professionalism (Westrick, Helms, McDonough \& Breland, 2009).

Regarding the analysis of the reasons for absenteeism - the focus of this research - previous studies have attempted to identify the causes for absenteeism among university students (Pithers \& Holland, 2007; Gump, 2006; Kottasz, 2005). According to them, the causes can be, among others, health problems, problems in the lecturerstudent and/or student-student relationship, the students' lack of interest towards the learning process, and difficulty to meet academic requirements (Álvarez \& López, 2011).

More specifically, Triadó-Ivern et al. (2013) analysed the reasons for absenteeism in six different degrees at the School of Economics and Business of the Universitat de Barcelona, Spain: Business Administration and Management, Economy, Marketing Techniques and Research, Sociology, Actuarial Science and Statistics. Through a survey, they identified 12 reasons for student absenteeism which they grouped into 4 factors, as shown in Table 1. In Triadó-Ivern, Aparicio-Chueca, Guàrdia-Olmos, Jaría-Chacón, Peró-Ceboller \& Elasri-Ejjaberi et al. (2014) the results supported the notion that students attending evening lectures perceive absenteeism 
differently (related to their job and enrolment in many credits) from those attending in the morning (they prefer to study in the library or attend test preparation services). However, all the students agreed that the teaching methodology, i.e., how the lecturers teach the subjects, was also very important.

López-Bonilla \& López-Bonilla (2015) analysed 28 determining factors of university absenteeism in the Tourism degree at the University of Seville, Spain. The authors concluded that the causes for absenteeism can be grouped into seven factors, as described in table 1, the teaching methodology being the most important (Triadó-Ivern et al., 2014).

Sarmento-dos-Santos, Chaves-Barboza \& Romero Díaz de la Guardia (2017), in their study at the Pedagogical High School from Namibe, Angola, detected 4 factors which are detailed in table 1.

Oldfield, Rodwell, Curry and Marks (2017) analysed the reasons by focusing on an English university and they concluded that students do not attend because of a lower engagement, social life commitments, work, deadlines (see also Ramchander, 2017) and mental health problems.

Therefore, this research seeks to analyse whether the reasons for absenteeism have changed after the implementation and consolidation of the EHEA model, which is supposed to make students become more involved.

Insert table 1 about here 


\section{Method}

\section{Sample}

UB's SEB featured nearly 7,100 undergraduates enrolled in five different bachelor degrees in the 2016-17 academic year.

Data was collected during the spring of 2017. A quantitative design was used with a non-probabilistic sample of 1,896 students enrolled in these three degrees: Business, Economy and Sociology. Each participant received all the necessary information for their consent, which was by all means voluntary, confidential and anonymous. The participants' sociodemographic profile appears in Table 2.

Insert Table 2 about here

\section{Questionnaire}

The questionnaire comprised 19 items (18 closed questions and 1 open question for additional comments) (see table 2), 5 sociodemographic items (gender, age, year, schedule and degree) and one question about lesson attendance. The questionnaire used was based on a previous scale applied in Triadó-Ivern et al. (2013). The items are described in table 1.

Student absenteeism is a real problem, but it is not easy to measure. In an attempt to overcome this lack of agreement regarding measurement, in the questionnaire, the participants were asked to answer to what extent they attended lessons and the results show that $55 \%$ of students 'always' attend ( $>80 \%$ ), while $39.2 \%$ do so 'regularly'(60\%-80\%), $5.8 \%$ of them attend 'little'(30\%-60\%) or 'very little' (< $30 \%)$ 
In order to analyse absenteeism, the questionnaire asked those students attending classes about the reasons for their classmates' absence. This means that the measurement of absenteeism was indirect, as the direct source was not available.

All the items were assessed through a 4-point scale, ranging from totally disagree (1) to totally agree (4). Figure 1 presents how the research field work was carried out. The analysis of reliability took a correct value (over 0.70 ), with a Cronbach's alpha of 0.70 , and it was statistically significant for Snedecor's $F$.

\section{Insert Figure 1 about here}

\section{Analysis}

Data analysis was performed by means of the SPSS 22 software package. In order to determine the structure of the scale, the components factor analysis method and the Oblimin rotation method were applied. The exploratory factor analysis was conducted in order to group the reasons why students skip class. A difference-of-means analysis was also performed using ANOVA. The ANOVA analysis was applied to identify the differences among students in terms of their year of study and their degree.

\section{Results}

\section{Difference of means}

All the reasons present high averages, most of them above 2 out of 4 . The main reason highlighted is 'because of the lecturers' teaching, the lessons are burdensome and/or boring', which reaches an average of 3.16. Next, with a score of 2.91, is 'because of the course, lessons become burdensome and/or boring'. 'The lecturer dictates notes or reads 
the slides' with a 2.81; and 'the lecturer does not make attendance compulsory' with an average of 2.78, are also highlighted reasons (see table 3).

In order to study absenteeism in more depth, a difference-of-means analysis (ANOVA) by year and degree was calculated. Regarding the year (see table 3), significant differences were detected. Students from the first two years present a similar behaviour as compared to the third and fourth years (in Spain, bachelor degrees last for 4 years). Thus, the students' behaviour is different at the beginning from what it is at the end. This result is expected as students in the last years know the curriculum better and can complement their profile by working or through a practicum.

When the analysis is conducted on the three different bachelor degrees at hand, significant differences are also detected (see table 3). It is worth saying, for instance, that for Business and Economy students, 'working' is not an important reason for absenteeism, while for Sociology students, it is the most important. This could be explained by the fact that the majority of these students are self-funding their studies. In addition, these students also find it important to follow a 'single evaluation', to have their 'schedules match', and to study 'simultaneous degrees'. Another example could be the use of 'test preparation services'. In this case, for Business and Economy students this reason is important but not so much for those studying Sociology. This might be due to the fact that the courses in this degree are conceptual rather than quantitative, the speciality of these services.

Insert table 3 about here

\section{Exploratory factor analysis}

In order to reduce the variables that contribute to dimensioning the absenteeism phenomenon, an exploratory factor analysis was performed, thus obtaining five factors 
which explain $53.20 \%$ of the total variance (see table 4 ).

The first factor includes the variables regarding the students' own planning. It explains $17.7 \%$ of the total variance and consists of variables related to, e.g., the single evaluation, schedule overlapping and work. Thus, the reasons which best explain absenteeism regard the students.

The second factor groups the variables regarding the teaching methodology. It explains $14.4 \%$ of the model and includes variables such as how the lessons are taught or the way the teacher explains the lessons.

The third factor weighs $8.2 \%$ of the total variance and includes variables regarding the learning methodology, such as 'they are repeating the course' or 'it is not compulsory to attend.'

Factor four comprises the variables concerning the characteristics of the course, i.e., the content of the course is simple and there exists sufficient material to prepare it on their own $(7.2 \%$ of the model variance).

As for the fifth factor, with an explanatory capacity of 5.6\%, it groups variables regarding the external sources available for students, such as the library and test preparation services.

Insert table 4 about here

In order to understand the reasons for absenteeism, these factors have been related to the year of study and the bachelor degree so as to detect differences. Firstly, regarding the course, the results show significant differences among years of study in all the factors, except the fourth one, which regards the course characteristics (see table 5). First-year students explain absenteeism mainly through external sources (F5), while 
second-year students think their own planning (F1) and the teaching methodology (F2) are more important. On the other hand, third-year students focus on their own planning (F1) and on the teaching (F2) and learning (F3) methodologies. Last-year students find all factors important. It seems that the reasons for absenteeism increase the higher the year.

Insert table 5 about here

The analysis of the relationship between the factors and the bachelor degree (see table 6) shows that there are also significant differences. In addition, Business students behave differently from Economy or Sociology ones, but they also have more reasons to be absent. Firstly, Business students give more importance to the teaching (F2) and learning (F3) methodologies and to external sources (F5). Secondly, Economy students find the learning methodology (F3) important, as well as and their own organisation (F1). Finally, the Sociology students' reasons concern their own planning (F1) and the teaching methodology (F2).

Insert Table 6 about here

\section{Discussion and conclusions}

The aim of this paper is to analyse the reasons for student absenteeism from the students' point of view. The results allow us to extract suggestions for every actor in the educational process.

Students have different opinions regarding the main reasons for absenteeism depending on their year of study and their degree. Regarding the years of study, students, early in the degree, think their classmates do not attend class mainly because 
the lecturer does not make attendance compulsory, while the reasons highlighted by students in the late years regard the way students organise and plan their own profile. By degrees, differences were also detected, and while Sociology students give more importance to the reasons regarding 'work', 'single evaluation' and 'schedule problems,' Business and Economy students give more value to 'test preparation services.' These findings allow us to answer the research question posed, as the reasons for absenteeism differ by year of study and degree, in contrast to previous studies (Triadó-Ivern et al., 2013; 2014).

The results also make it possible to identify five factors which enhance the explanation of the reasons for absenteeism: (1) student's own planning, (2) teaching methodology, (3) learning methodology, (4) course characteristics and (5) external sources ( similar to Sarmento-dos-Santos et al., 2017, but not directly related to Oldfield et al., 2017 or Ramchander, 2017). We should also note that the factor that best explains the reasons for absenteeism in the sample analysed regards the students and how they organise, plan and design their academic profile, while the second one concerns the teaching methodology. This is another difference from the existing literature because, according to Triadó-Ivern et al. (2014), the teaching methodology was the most highlighted reason in their studies.

The main contribution of this research is the identification of differences in the perception of students on the reasons for absenteeism depending on their year of study and their degree. This means that actions to decrease absenteeism need a customised plan and design, i.e., in this case the same strategy does not fit all. The second contribution is the detection of a difference of responsibilities, i.e., the results show a difference in perceptions as students are able to identify their responsibility for the problem (Barlow \& Fleischer, 2011), and it is not only because of the lecturers (in 
contrast to Triadó-Ivern et al., 2013; 2014; López Bonilla \& López-Bonilla, 2015). Finally, it seems that the implementation of the EHEA has had an impact on the students' awareness of their responsibility, although not in the expected sense. An indepth analysis of the phenomenon is needed to identify the differences in the implementation pattern of the model.

The main implications of this study are for students, lecturers and university and country governments. They concern students because the results show that they should plan and organise their own profile better. As for lecturers, they concern both subject design and the learning methodology implemented. In addition, considering the yearrelated differences we found, teachers should try to make students loyal (increase their engagement) early in the degree so that they get used to attending lessons. A higher involvement of the institutions would probably lead to a better learning process which would also impact the reduction of absenteeism. At this level, it might also be positive to create a common protocol of materials available and teaching methodology per year. Another important aspect to highlight is the need for better communication in all directions: all the parties involved should explain their reasons but also listen to the others.'

This research is not free of limitations. The most important, as mentioned, has been the data gathering, given that an indirect methodology was used. Also, the School where the research was performed is one of the largest of the University and this may have conditioned the results.

Future research should focus on gathering data about lecturers' perceptions on student absenteeism and compare them both to identify possible gaps, and thus propose improvement actions. 


\section{ACKNOWLEDGEMENTS}

This project has been developed thanks to a research project REDIC16-1600 funded by the Institute of Education Sciences (ICE) of the Universitat de Barcelona.

\section{Notes on contributors}

Xavier M. Triadó Ivern is an associate professor at the University of Barcelona. He is the director of the IDP-ICE, the Institute of Educational Science at the University of Barcelona. He is currently a member of the Research Group in Business at the University of Barcelona.

Pilar Aparicio-Chueca is an associate professor at the Business Department at the University of Barcelona. She is the director of Master's Degree in Sport Business Management at the University of Barcelona. Her major research areas are health economy, sports management and innovations and education research.

Amal Elasri-Ejjaberi is a doctoral researcher at the Business Department at the University of Barcelona. Her major areas of empirical fieldwork include: sport management and higher education. She is currently a member of the Research Group in Business at the University of Barcelona.

Irene Maestro-Yarza is an associate professor at the Department of Economic History, Institutions and Policy and World Economy at the University of Barcelona. Her currently major research areas are the Economics of Development, the Development Cooperation and the Asian Economies.

Merce Bernardo is an associate professor at the Department of Business at the University of Barcelona. Her main interests on research are related to quality management and has also 
investigated on the students' competences and the implementation of alternative teaching methodologies to improve students learning, such as games.

Pilar Presas is a postdoctoral researcher at the Department of Business at the University of Barcelona. Degree in Tourism, Master in Tourism Management and Planning, and PhD in Tourism, Law and Business at the University of Girona. Research interests are family businesses, social responsibility and tourism.

\section{References}

Álvarez, P. R., \& López, D. (2011). El absentismo en la enseñanza universitaria: Un obstáculo para la participación y el trabajo autónomo del alumnado. Bordón. Revista de pedagogía, 63, 43-56.

Barlow, J., \& Fleischer, S., (2011). Student absenteeism: Whose responsibility? Innovations in Education and Teaching International, 48, 227-237.

de Jorge Moreno, J., Gil, L. G., de Lucas, F. M., \& Triguero, M. S. (2011). Evidencia empírica de los motivos del absentismo en los estudiantes universitarios. Revista de Investigación en Educación, 9, 76-90

Driver, R. W., \& Watson, C. J. (1989). Construct validity of voluntary and involuntary absenteeism. Journal of Business and Psychology, 4, 109-118.

EU (1999). Bologna Declaration, European Commission - Education and Training Supporting education and training in Europe and beyond. Retrieved from: http://ec.europa.eu/education/policy/higher-education/bologna-process_en

Gump, E., (2006). Guess who's not coming to class: Students attitudes as indicators of attendance. Educational Studies, 32, 39-46.

Kottasz, R., (2005). Reasons for student non-attendance at lectures and tutorials: An analysis. Investigations in university teaching and learning, 2, 5-16. 
Landin, M., \& Pérez, J. (2015). Class attendance and academic achievement of pharmacy students in a European University. Currents in Pharmacy Teaching and Learning, 7, 78-83.

López-Bonilla, J. M., \& López-Bonilla, L. M. (2015). The multidimensional structure of university absenteeism: an exploratory study. Innovations in Education and Teaching International, 52, 185-195.

Lozano, M., Romano, I. Y., \& Segovia, M. M. (2014). Efectos del trabajo en grupo en el rendimiento académico y en el grado de satisfacción del alumnado. Comunicación al I Seminario Iberoamericano de Innovación Docente de la Universidad Pablo de Olavide, 20-21 de noviembre de 2014. Recuperado de: http://www.upo.es/ocs/index.php/sididoupo/sidiupo/schedConf/presentations

Moore, S., Armstrong, C., \& Pearson, J. (2008). Lecture absenteeism among students in higher education: A valuable route to understanding student motivation. Journal of Higher Education Policy and Management, 30, 15-24.

OECD (2018). Spending on tertiary education. Retrieved from: https://data.oecd.org/eduresource/spending-on-tertiary-education.htm\#indicatorchart

Oldfield, J., Rodwell, J., Curry, L., \& Marks, G., (2018). Psychological and demographic predictors of undergraduate non-attendance at university lectures and seminars. Journal of Further and Higher Education, 28, 509-523

Paisey, C., \& Paisey, N. (2004). Student attendance in an accounting module: Reasons for non-attendance and the effect on academic performance at a Scottish university. Accounting education, 13, 39-53. 
Pithers, B., \& Holland, T. (2007,). I'm too busy and they are just so boring!

Students and lectures. Paper presented at IUT Conference, Broadway, Australia.

Ramchander, M. (2017). Contextual Factors Influencing Student Absenteeism at a Higher Education Institution in South Africa. Africa Education Review, 14, 114

Romer, D. (1993). Do students go to class? Should they?. Journal of Economic Perspectives, 7, 167-174.

Sarmento-dos-Santos, A. P., Chaves-Barboza, E., \& Romero Díaz de la Guardia, J. J. (2017). Variables pedagógicas que causan e influyen el absentismo estudiantil en las clases de matemática de la escuela superior pedagógica de Namibe-Angola. European Scientific Journal, 13, 192-210.

Stoner, S. C., \& Fincham, J. E. (2012). Faculty role in classroom engagement and attendance. American Journal of Pharmaceutical Education, 76, 75.

Triadó-Ivern, X. M., Aparicio-Chueca, P., Guàrdia-Olmos, J., Peró-Cebollero, M., \& Jaría-Chacón, N., (2013). Empirical approach to the analysis of university student absenteeism: Proposal of a questionnaire for students to evaluate the possible causes. Quality \& Quantity, 47, 2281-2288.

Triadó-Ivern, X. M., Aparicio-Chueca, P., Guàrdia-Olmos, J., Jaría-Chacón, N., PeróCebollero, M. \& Elasri-Ejjaberi, A. (2014). University student absenteeism: Factors and profiles. In S. Mukerji \& P. Tripathi (Ed.), Handbook of Research on Transnational Higher Education (pp. 454-466). Hershey, PA: IGI Global.

Walker, C., Fleischer, S.,, \& Winn, S. (2008). A path analysis of first-year social science students' engagement with their degree and level 1 academic outcome. Enhancing Learning in the Social Sciences, 1, 1-19. 
Westrick, S. C., Helms, K. L., McDonough, S. K., \& Breland, M. L. (2009). Factors influencing pharmacy students' attendance decisions in large lectures. American Journal of Pharmaceutical Education, 73, 83. 